\title{
Leveraging quorum sensing system for automatic coordination of Escherichia coli growth and lactic acid biosynthesis
}

\author{
Chang Ge, Shunqi Run, Hongkai Jia and Pingfang Tian * (1)
}

\begin{abstract}
Purpose: Overproduction of desired metabolites usually sacrifices cell growth. Here we report that quorum sensing (QS) can be exploited to coordinate cell growth and lactic acid production in Escherichia coli.

Methods: We engineered two QS strains: one strain overexpressing acyl-homoserine lactone (AHL) synthesis genes $(" \mathrm{ON}$ "), the other strain overexpressing both AHL synthesis and degradation gene (aiiA) ("ON to semi-OFF"). To clarify the impact of the QS system on lactic acid production, D-lactate dehydrogenase gene IdhA was deleted from the $E$. coli genome, and Enhanced Green Fluorescence Protein (eGFP) was used as the reporter.

Results: Compared to the "ON" strain, the "ON to semi-OFF" strain showed delayed log growth and decreased egfp expression at stationary phase. When egfp was replaced by IdhA for lactic acid production, compared to the wildtype strain, the "ON to semi-OFF" strain demonstrated $231.9 \%$ and $117.3 \%$ increase in D-lactic acid titer and spacetime yield, respectively, while the "ON" strain demonstrated $83.6 \%, 31 \%$, and 36\% increase in growth rate, maximum $\mathrm{OD}_{600}$, and glucose consumption rate, respectively. Quantitative real-time $\mathrm{PCR}$ revealed that both $/ \mathrm{dh} A$ and the genes for phosphotransferase system were up-regulated in IdhA-overexpressing "ON" strain compared to the strain only harboring QS system. Moreover, the "ON" strain showed considerable increase in glucose consumption after a short lag phase. Compared to the reference strain harboring only IdhA gene in vector, both the "ON" and "ON to semi-OFF" strains demonstrated synchronization between cell growth and D-lactic acid production.
\end{abstract}

Conclusions: Collectively, QS can be leveraged to coordinate microbial growth and product formation.

Keywords: E. coli, Quorum sensing, Lactic acid, Cell growth, Automatic regulation

\section{Background}

One primary mission of microbial metabolic engineering and synthetic biology is the high-level production of intended metabolites. To this end, scientists have developed a set of strategies, including overexpression of key enzymes, deletion or attenuation of competing pathways (Jiang et al. 2021; Wu et al., 2020a, b; Mazumdar et al. 2010), management of ATP (Lan and Liao 2012),

*Correspondence: tianpf@mail.buct.edu.cn

Beijing Key Laboratory of Bioprocess, College of Life Science and Technology, Beijing University of Chemical Technology, Beijing 100029, People's Republic of China and adjustment of cofactors (Ling et al. 2018). However, these strategies, in most cases, compromise cell growth and hamper product formation (Liu et al. 2019). To coordinate cell growth and production formation, both static and dynamic control approaches have been developed. Static control strategies include in situ recovery of desired metabolites (Kaur et al. 2015), optimization of fermentation conditions, improvement of cell tolerance (Lou et al. 2018), enzyme immobilization, and enzyme modification to circumvent feedback inhibition (Chen et al. 2014). Unlike static control approaches that ignore the changing environments, dynamic approaches enable real-time sensing of changing settings (Zhou et al. 2012; 
Tan and Prather 2017; Harder et al. 2018). For instance, metabolite-sensitive biosensors can timely mitigate metabolic stress (Xu et al. 2014; Peters et al. 2018).

Apart from the aforementioned strategies, microbes have evolved exquisite mechanisms to coordinate cell growth and metabolite accumulation. For instance, quorum sensing (QS) represents a cell-to-cell communication tailored for governing cell density and other biochemical events (You et al. 2004; Moreno-Gámez et al., 2017). The LuxI/R QS system from Vibrio fischeri relies on an extracellular signal molecule termed autoinducers such as $\mathrm{N}$-acyl homoserine lactone (AHL) (Papenfort and Bassler 2016). AHL is a typical autoinducer identified in bacteria-harboring enzymes LuxI ( $\mathrm{N}$-acyl homoserine lactone synthase) and LuxR (AHL-binding transcription inducer). The LuxI catalyzes the formation of AHL, while luxR encodes an AHL-binding transcription factor (Fuqua et al. 1994). Interestingly, the enzyme, AiiA ( $\mathrm{N}$-acyl homoserine lactone hydrolase), from Bacillus thuringiensis can degrade AHL and thereby quench QS (Dong et al. 2000; Dong et al. 2001; Dong et al. 2002; Thomas et al. 2005). AHL can pass through the cell membrane, and when AHL concentration reaches a threshold, cells start to orchestrate a series of biochemical events including bioluminescence, biofilm formation, and signal transduction. It is costly for a single cell to accomplish all the aforementioned events. However, the QS mechanism is cost-effective, as it is a collective behavior. The LuxI/R QS represents a naturally occurring strategy to balance cell growth and other events, and holds promise to switch gene expression. Apart from LuxI-type QS system, other QS systems can also coordinate cell growth and other events (Balestrino et al. 2005; Sun et al. 2016).

High-level product formation, in most cases, imposes a heavy burden on cell growth. For instance, buildup of lactic acid impairs cell growth and therefore restricts its overproduction (Zhou et al., 2006a, b). As an important metabolism, the biosynthesis of D-lactic acid is mainly accomplished by D-lactic acid dehydrogenase (LdhA) (Bunch et al. 1997), a reversible enzyme in Escherichia coli. While low concentration of lactic acid is beneficial for cell growth, a high concentration of lactic acid inhibits cell growth (Zhou et al., 2006a, b). Given the close relation between QS and cell growth, the factors influencing cell growth should also affect QS activity. That is, the QS system functionally responds to metabolite stress. To date, QS has been exploited for metabolic engineering and synthetic biology purposes. For example, QS was exploited for an automatic switch of metabolic states (Kim et al. 2017). Also, QS is capable of spatial regulation of gene expression when coupled with RNA interference (RNAi) (Williams et al. 2015) or CRISPR-dCas9 (Gupta et al. 2017; Doong et al. 2018).
More importantly, QS has been harnessed for automatic drug delivery (Din et al. 2016).

Given the above information, we conjecture that reengineering of the innate QS circuit holds promise to balance cell growth and lactic acid formation. To test this hypothesis, lactic acid synthesis gene $l d h A$ was knocked out from the $E$. coli genome, leading to a chassis cell. Next, two QS-based strains were engineered. One strain harboring AHL synthesis genes was named "ON". The other strain harboring both AHL synthesis and degradation genes was designated "ON to semi-OFF". Enhanced green fluorescent protein (eGFP) was used as the reporter to characterize the engineered QS systems. Coexpression of $l d h A$ and QS cassette was to dissect the influences of two QS systems on lactic acid production. Detailed analysis of protein expression, cell growth, glucose consumption, D-lactic acid, and byproducts was to decipher the impacts of QS circuits on microbial metabolisms. Quantitative real-time PCR (qRT-PCR) analysis of the genes related to QS and glucose metabolisms was to clarify the underlying mechanisms. Overall, this study aims to develop a QS-based dynamic control approach for coordinating cell growth and lactic acid production.

\section{Materials and methods}

\section{Strain, vector, medium, and reagents}

Strains and vectors used in this study are listed in Table S1. E. coli BL21(DE3) was purchased from Biomed Co. Ltd. Strains were stored in glycerol-containing LuriaBertani medium at $-20^{\circ} \mathrm{C}$. Prior to culture, they were incubated to test tubes containing $4 \mathrm{~mL}$ Luria-Bertani medium and appropriate antibiotics, and shaken at $180 \times$ $g$ and $37^{\circ} \mathrm{C}$. For seed culture, E. coli was incubated in M9 minimal medium containing the following components per liter: glucose, $3.1 \mathrm{~g} ; \mathrm{NaCl}, 0.5 \mathrm{~g} ; \mathrm{Na}_{2} \mathrm{HPO}_{4} \cdot 7 \mathrm{H}_{2} \mathrm{O}$, $12.8 \mathrm{~g} ; \mathrm{KH}_{2} \mathrm{PO}_{4}, 3.0 \mathrm{~g} ; \mathrm{NH}_{4} \mathrm{Cl}, 1.0 \mathrm{~g} ; \mathrm{MgSO}_{4}, 0.492 \mathrm{~g}$; $\mathrm{CaCl}_{2} \cdot 6 \mathrm{H}_{2} \mathrm{O}, 0.0219 \mathrm{~g}$. One percent $(\mathrm{v} / \mathrm{v})$ of seed culture was transferred to a $250-\mathrm{mL}$ flask containing $100 \mathrm{~mL}$ M9 minimal broth and appropriate antibiotics, and cultured in a shaker at $150 \times g$ and $30{ }^{\circ} \mathrm{C}$. The concentrations of kanamycin and chloramphenicol were $50 \mu \mathrm{g} / \mathrm{mL}$ and 34 $\mu \mathrm{g} / \mathrm{mL}$, respectively. Vectors pKD46, pKD13, and pCP20 were used for gene knockout (Datsenko and Wanner, 2000). Other vectors used in this study were derived from vector pACYC-Duet1 or pET-28a. Restriction endonucleases and DNA polymerase were purchased from TaKaRa (Dalian, China). Kits for ligation were purchased from Thermo (Beijing, China). Kits for plasmid isolation and DNA purification were purchased from Biomed (Beijing, China). DNA marker and other reagents were purchased from Bioroyee (Beijing, China). Gene synthesis and DNA sequencing were accomplished by BGI (Beijing, China) and Beijing Syngentech Co., Ltd. Standards 
for metabolite assay were products of Sigma (Beijing, China).

\section{Gene knockout}

The E. coli ldhA gene was knocked out using the reported method (Datsenko and Wanner, 2000). To obtain cassette 52nt-FRT-Kan-FRT-50nt, PCR primers were designed according to the 52-nt upstream and 50-nt downstream sequence immediately flanking the $l d h A$ gene (Table S2). The kanamycin resistance gene (KanR) and two FRT (FLP recognition target) sites were cloned by PCR from vector pKD13. The $50-\mu \mathrm{L}$ mixture for PCR reaction included 25 $\mu \mathrm{L}$ of Premix PrimeSTAR ${ }^{\circledR} \mathrm{HS}, 1 \mathrm{ng}$ of pKD13, $0.4 \mathrm{mM}$ of forward, and reverse primers of pKD13. The protocol for PCR reaction includes initial denaturation at $98^{\circ} \mathrm{C}$ for 2 min, followed by 30 cycles of $98^{\circ} \mathrm{C}$ for $10 \mathrm{~s}, 60^{\circ} \mathrm{C}$ for $50 \mathrm{~s}$, $72{ }^{\circ} \mathrm{C}$ for $110 \mathrm{~s}$, and $72^{\circ} \mathrm{C}$ for $10 \mathrm{~min}$. The Dpn I endonuclease was used to digest vector pKD13.

The competent $E$. coli BL21 cells were electro-transformed with vector pKD46 and incubated in Luria-Bertani medium at $30^{\circ} \mathrm{C}$ for $1 \mathrm{~h}$. Positive recombinants were screened by Luria-Bertani ampicillin plates. After overnight cultivation, positive recombinants were confirmed by colony PCR. The strains harboring vector pKD46 were grown in Luria-Bertani medium to reach $\mathrm{OD}_{600}$ of 0.12-0.2. Next, $100 \mathrm{mM} \mathrm{L}$-arabinose was used to induce recombinase expression at $37^{\circ} \mathrm{C}$ for $1.5 \mathrm{~h}$. The strains were concentrated by 30 -fold at $4{ }^{\circ} \mathrm{C}$ and washed twice with cold distilled water. Electroporation was performed in Bio-rad Micropulser with $100 \mu \mathrm{L}$ competent cells and $5 \mu \mathrm{L}$ PCR products added in a $0.2-\mathrm{cm}$ cuvette. The transformed cells were recovered in $890 \mu \mathrm{L}$ Luria-Bertani medium at $30^{\circ} \mathrm{C}$ for $2 \mathrm{~h}$, and then grown in kanamycin Luria-Bertani plate at $30{ }^{\circ} \mathrm{C}$ for $72 \mathrm{~h}$. Positive clones were confirmed by colony PCR and DNA sequencing.

Vector pCP20 harbors ampicillin and chloramphenicol resistance genes $\left(\mathrm{Amp}^{\mathrm{R}}\right.$ and $\left.\mathrm{Cm}^{\mathrm{R}}\right)$, temperature-sensitive replication, and FLP sequence for acting on two FRT sites. After pCP20 was transformed into competent $E$. coli cells, the kanamycin resistance gene on E. coli chromosome was eliminated upon cultivation at $30^{\circ} \mathrm{C}$ for 24 $h$. The resulting $\operatorname{Kan}^{\mathrm{R}}$ mutant was continuously grown in an antibiotics-free Luria-Bertani plate at $42^{\circ} \mathrm{C}$ for $3-5$ generations of subculture, and then grew in Luria-Bertani plate containing ampicillin and chloramphenicol to examine whether the strains still harbored vector pCP20. Mutant E. coli $\Delta l d h A$ was confirmed by colony PCR and DNA sequencing.

\section{Construction of recombinants}

The AHL synthesis gene cluster luxI-luxR from $V$. fischeri ES114 (Papenfort and Bassler 2016) was cloned by PCR and inserted into vector pACYCDuet1 at BamH I/EcoR
I, leading to vector pluxIR which served as the common vector for all recombinant strains (Fig.1). To construct an AHL-responsive vector, the original T7 promoter in vector pET-28a(+) was replaced by an AHL-inducible luxi promoter, resulting in vector $\mathrm{pET}-P_{\text {luxi }}$. To determine the influence of AHL on lactic acid production, a set of vectors were constructed. The genes-egfp (followed by ssrA degradation tag: GCTGCTAACGACGAAAACTAC GCTCTGGCTGCT), ldhA, and aiiA-were independently inserted into vector pET-P luxi at EcoRI/Hind III, BamHI/EcoRI, and HindIII/XhoI sites, resulting in vectors $\mathrm{pET}-P_{\text {luxi }}$ :egfp, $\mathrm{pET}-P_{\text {luxi }}$ ldhA, and $\mathrm{pET}-P_{\text {luxi: }}:$ aiiA, respectively. The aiiA gene tailored for AHL degradation was cloned from $B$. thuringiensis.

To determine the effects of AiiA on egfp expression and lactic acid production, its coding gene aii $A$ was equipped with a moderate strength of RBS (AAGTTAAGAGGC AAGA) and then inserted into vectors pET- $P_{l u x i}: e g f p$ and pET- $P_{l u x i}: l d h A$ at Hind III/Xho I sites, resulting in vectors pET-P $P_{\text {luxi }}$ egfp-aiiA and pET-P luxi: ldhA-aiiA, respectively. To vary aiiA expression, the aiiA gene with weak or strong RBS (weak: CACCATACACTG; strong: AAG GAGGTTTGGA) was independently inserted into vector pET-P luxi $:$ ldhA at Hind III/Xho I sites, leading to vector pET-P $P_{\text {luxi }}: l d h A$-aiiA(weak) and $\mathrm{pET}-P_{\text {luxi }}: l d h A$ aiiA(strong), respectively. After the above vectors were independently transformed into competent $E$. coli $\Delta l d h A$ cells, we obtained seven recombinant strains named Q01, Q02, Q03, Q04, Q05, Q06, and Q07 (Table S1). To exploit AHL for coordinated gene expression, the vector pluxIR was transformed into above seven recombinant strains, resulting in recombinant strains Q11, Q12, Q13, Q14, Q15, Q16, and Q17, respectively. The control strains were constructed using empty pET- and pACYC-series vectors, including $\mathrm{C} 01, \mathrm{C} 02, \mathrm{C} 03, \mathrm{C} 04$, and $\mathrm{C} 05$. We expected that the strains overexpressing AHL synthesis gene exhibited "ON" state, while the strain coexpressing AHL synthesis and degradation gene manifested "ON to semi-OFF" state. All primers are listed in Table S2.

\section{SDS-PAGE analysis}

To determine whether the engineered QS cassette functioned properly in E. coli, the strains were independently inoculated in $250 \mathrm{~mL}$ shake-flasks, each containing 100 $\mathrm{mL}$ Luria-Bertani medium and antibiotics as appropriate. After $3 \mathrm{~h}$ cultivation, $0.5 \mathrm{mM}$ IPTG was added to induce protein expression. After $16 \mathrm{~h}$ shaking cultivation at $150 \times g$ and $37{ }^{\circ} \mathrm{C}$, cells were harvested by centrifugation at $7379 \times g$ for $10 \mathrm{~min}$, and then mixed with $4 \times$ SDS-polyacrylamide gel electrophoresis (SDS-PAGE) loading buffer and boiled for $5 \mathrm{~min}$. Protein expression was analyzed by $12 \%(\mathrm{w} / \mathrm{v})$ SDS-PAGE with cellfree extract under denaturing conditions. Mini-Protein 


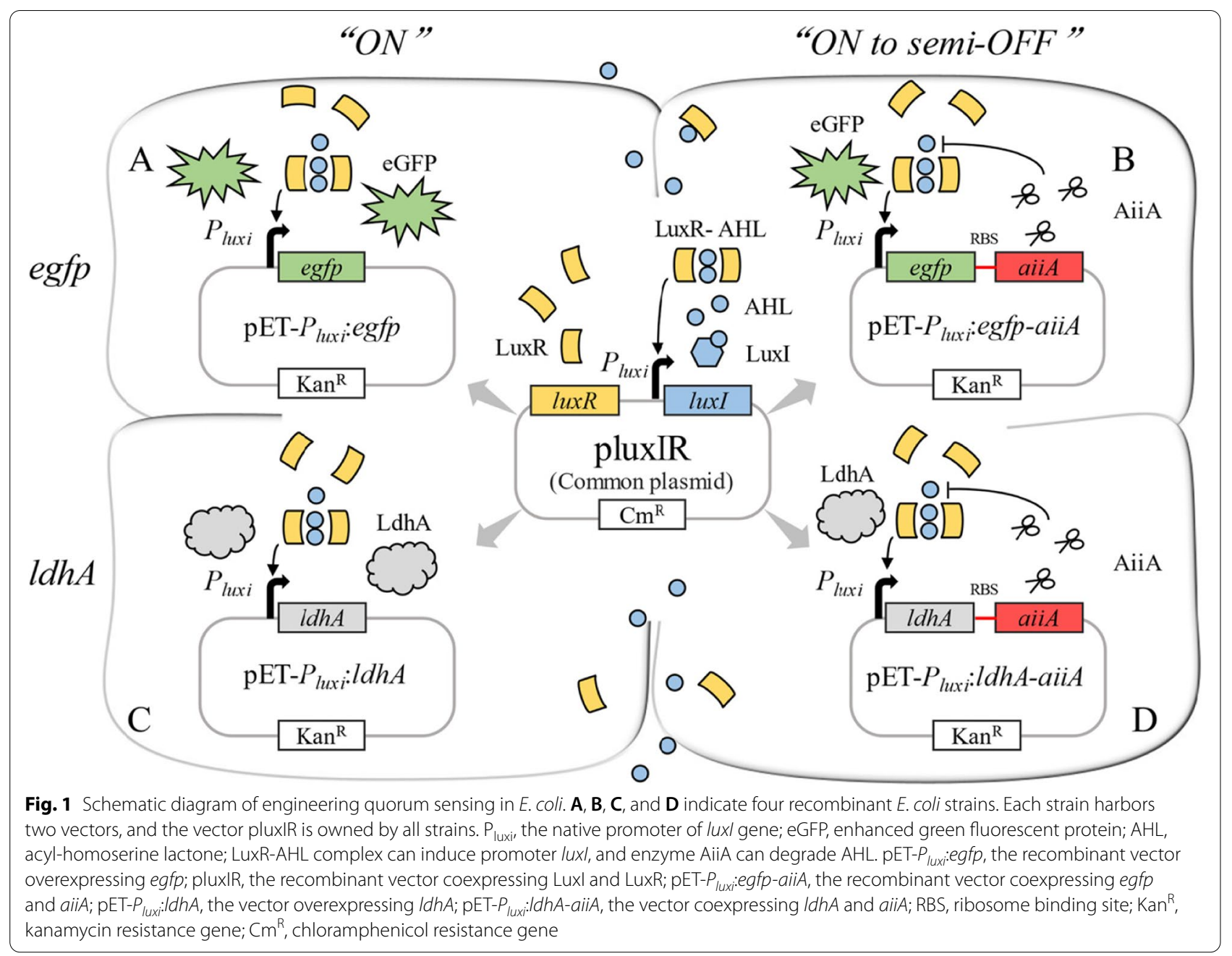

III Electrophoresis System (Bio-Rad, USA) was used to perform this operation. Coomassie Brilliant Blue R-250 $(0.2 \%, \mathrm{w} / \mathrm{v})$ was used to stain proteins on the gel, and protein concentration was measured by Bradford method with bovine serum albumin (BSA) as standard protein (Table S3).

\section{Determination of relative fluorescence}

To investigate eGFP expression, strains were grown in shake-flasks at $37^{\circ} \mathrm{C}$. Samples were taken every $2 \mathrm{~h}$ from 0 to $46 \mathrm{~h}$, and $200 \mu \mathrm{L}$ fermentation broth was added into a 96-well microtiter plate (Corning, NY, USA). To avoid fluorescence quenching, samples were stored in the dark at $4^{\circ} \mathrm{C}$ before the instrument was ready. Fluorescence intensity was measured using the Enspira microplate reader (PerkinElmer, Singapore) at $485 \mathrm{~nm}$ excitation wavelength and $9.5 \mathrm{~mm}$ measurement height. Relative fluorescence intensity was defined as the fluorescence value divided by $\mathrm{OD}_{600}$.

\section{Microscopic observation of fluorescence}

To directly view eGFP expression, strains were independently cultivated in shake-flasks, and fermentation broth was sampled at $8 \mathrm{~h}, 20 \mathrm{~h}$, and $32 \mathrm{~h}$ and stored in the dark at $-20{ }^{\circ} \mathrm{C}$ before the microscope was ready. For microscopic observation, $30 \mu \mathrm{L}$ sample was added on a microscope slide (Thermo Fisher Scientific, MA, USA), and an equal volume of a mixture containing glycerol and phosphate buffer saline (PBS) at $\mathrm{pH} 7.4$ was used as a sealant, which was under a cover glass without air bubble. Leica SP8 laser scanning confocal microscopes using Leica DMC2900 imaging system (Leica, Wetzlar, Germany) was set to eGFP mode with $40 \times$ objective and scale bar of $20 \mu \mathrm{M}$.

\section{Enzyme activity assay}

To measure the LdhA activity of Q12, Q15, Q16, and Q17, broths were sampled at different time points (8 $\mathrm{h}, 14 \mathrm{~h}, 20 \mathrm{~h}, 32 \mathrm{~h}$, and $48 \mathrm{~h}$ ), and then centrifuged at $7379 \times g$ for $10 \mathrm{~min}$. The harvested cells were washed 
twice using $100 \mathrm{mM}$ PBS ( $\mathrm{pH}$ 6.5), and then sonicated and centrifuged at $10,625 \times g$ for $10 \mathrm{~min}$. Proteins were quantified using Bicinchoninic acid (BCA) assay kit (Bioroyee, Beijing, China). $20 \mu \mathrm{L}$ supernatant was mixed with $200 \mu \mathrm{L} \mathrm{BCA}$ assay solution and incubated at $60^{\circ} \mathrm{C}$ for $30 \mathrm{~min}$. When the mixture was cooled to room temperature, absorbance at $570 \mathrm{~nm}$ was measured using a microplate reader. The LdhA activity was determined by lactate dehydrogenase (LDH) kit (Beijing Xinhualvyuan Science and Technology, Beijing, China), which can spectrophotometrically analyze the decrease rate of absorbance at $340 \mathrm{~nm}$ corresponding to NADH oxidation at $37^{\circ} \mathrm{C}$. This decrease rate is named as $\Delta \mathrm{A} / \mathrm{min}$. The reaction mixture consisted of $0.05 \mathrm{~mL}$ supernatant, $2.0 \mathrm{~mL} \mathrm{LDH}$ assay solution, and $0.2 \mathrm{~mL}$ pyruvate solution. After pyruvate solution was added into the reaction mixture, enzyme activity was immediately measured. The specific activity formula is $\operatorname{LdhA}(\mathrm{U} / \mathrm{mg})=\Delta \mathrm{A} /$ $\min *(106 / 6220) *(2.25 / 0.05) /$ protein concentration $=\Delta \mathrm{A} /$

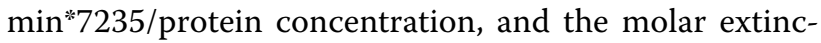
tion coefficient is $6220 \mathrm{M}-1 \mathrm{~cm}-1$ at $340 \mathrm{~nm}$.

\section{Determination of relative transcriptional levels}

To clarify how the "ON" mode of LdhA expression affected glycolysis and glucose phosphotransferase system (PTS) and to confirm the AiiA expression under different strength of RBS, qRT-PCR was performed. The strain Q12 and the reference strains $\mathrm{C} 01$ and $\mathrm{C} 02$ were sampled at different time points and harvested by centrifugation. RNA was isolated using QIAamp RNA Blood Mini Kit (Qiagen, Duesseldorf, Germany). The same RNA extraction was also performed for Q15, Q16, and Q17. After RNase-free DNase was added, cDNA was synthesized through SuperScript III Reverse Transcriptase (Invitrogen, CA, USA). Next, qRT-PCR analysis was carried out using the resultant cDNA by ABI ViiA 7 RealTime PCR System (Thermo Fisher Scientific, MA, USA). The 16S rRNA coding gene was used as the control to determine the relative expression levels of genes $l d h A$, gapA, gapC, ptsH, ptsI, pykF, and aiiA.

\section{Analytical methods}

Cell concentration was determined by microplate reader at $600 \mathrm{~nm}$ with $200 \mu \mathrm{L}$ fermentation broth added in a cuvette. The fermentation broth was centrifuged at $10,625 \times g$ for $10 \mathrm{~min}$, and the supernatant was filtered through a $0.22-\mu \mathrm{M}$ PES membrane. Metabolites including lactic acid and acetic acid were measured by a highperformance liquid chromatography (HPLC) system (Shimazu, Kyoto, Japan) equipped with a $\mathrm{C}_{18}$ column and an SPD-20A UV detector at $210 \mathrm{~nm}$. Column temperature was maintained at $25{ }^{\circ} \mathrm{C}$, and the mobile phase was $0.05 \%$ phosphoric acid at a flow rate of $0.8 \mathrm{~mL}$ $\mathrm{min}^{-1}$. Injection volume was $20 \mu \mathrm{L}$. Glucose and L-lactic acid were measured by SBA-40E biosensor (Shandong, China). The reaction and cleaning time were $20 \mathrm{~s}$ and 10 $\mathrm{s}$, respectively. The injection volume was $25 \mu \mathrm{L}$. D-lactic acid is the total lactic acid minus L-lactic acid.

To analyze AHL and its derivatives, cell-free supernatant was extracted with acidified ethyl acetate (by $0.05 \%$ formic acid). The extraction was performed in triplicate, and mixture was evaporated to dryness. The extract was dissolved in methanol, filtered through a $0.45-\mu \mathrm{m}$ organic membrane and followed by UPLC-MS/MS analysis (Waters ACQUITY UPLC/Quattro Premier, USA, Massachusetts). A Waters ACQUITY SDS $\mathrm{C}_{18}$ column was utilized as the solid phase and maintained at $45^{\circ} \mathrm{C}$. Mobile phase consists of $0.1 \%$ acetic acid (A) and acetonitrile (B). Gradient elution was conducted with the profile of $99 \%$ A at the first $1 \mathrm{~min}, 40 \%$ A from 2 to $4 \mathrm{~min}, 100 \% \mathrm{~B}$ from 5 to $8 \mathrm{~min}, 100 \%$ B from 9 to $11 \mathrm{~min}$, and $99 \%$ A from 12 to $13 \mathrm{~min}$. Flow rate was $0.3 \mathrm{~mL} / \mathrm{min}$. Mass detection was performed in ES+ ionization mode and data were analyzed by Masslynx V4.1 software.

\section{Characterization of recombinants}

In this study, QS was exploited to coordinate cell growth and lactic acid production in E. coli. In doing so, we constructed two vectors carrying different resistance genes and replicons. The medium-copy vector, pluxIR, carries luxI-luxR gene cluster to automatically synthesize AHL and constitutively express AHL-binding protein LuxR (Fig.1B). The high-copy vector pET- $P_{\text {luxi }}$ harbors a $P_{\text {luxi }}$ promoter and a $\mathrm{pET}-28 \mathrm{a}(+)$ backbone, where gene expression is controlled by QS. Due to this architecture, the vector pluxIR could express LuxR-AHL, which in turn induced the expression of gene on vector $\mathrm{pET}-P_{\text {luxi }}$. With the increase of cell density, the transcriptional regulator LuxR-AHL would bind $P_{l u x i}$ promoter and elicit the transcription of downstream gene. Apart from this inducible expression, the QS-based "ON to semi-OFF" expression was realized by using pluxIR and pET- $P_{\text {luxi }}$ :aiiA, where the aiiA gene was inserted downstream of the $P_{l u x i}$ promoter on vector pET- $P_{\text {luxi }}$. Since pluxIR was used to express the LuxR-AHL complex which in turn initiated the transcription of aiiA on vector pET- $P_{\text {luxi }}$ :aiiA, the resulting AiiA would repress the transcription of $P_{l u x i}$ promoter-driven luxi and aiiA due to AiiA-mediated AHL degradation, therefore leading to "OFF" state. Notably, this "OFF" state was transient because AiiA expression was rapidly turned off. When AiiA concentration decreased to a threshold at which AHL could not be completely degraded, QS was then turned on and gene expression was restarted. The above architecture was designated as "ON to semi-OFF". In such an architecture, the LuxR-AHL complex activated gene transcription and 
thereby led to constant "ON" state (Fig. 1). By contrast, the combination of LuxR-AHL and AiiA triggered not only AHL synthesis but also its degradation, leading to "ON to semi-OFF" state (Fig. 1).

This engineered system would dynamically control the expression of gene downstream of $P_{\text {luxi }}$ promoter on vector pET- $P_{l u x i}$ or the gene between $P_{l u x i}$ promoter and aiiA gene on vector pET- $P_{\text {luxi }}$ :aiiA where the transcription initiation of target gene is earlier than aiiA gene. RBS was inserted upstream of aiiA to allow aiiA and target gene sharing a cassette. To test the two engineered QS circuits, eGFP was employed as the reporter (Fig. 1, strain A and B). To confirm the QS circuits, egfp was replaced by $l d h A$ (Fig. 1, strain C and D). To exclude the influence of native ldhA gene on QS circuits, it was deleted from E. coli genome through $\lambda$ Red recombination method. To do so, three vectors, viz, pkD13, pkD46, and pCP20 were used
(Table S1). The vector, pKD13, was used as PCR template including FRT, kanamycin resistance gene, and homology arms of $l d h A$ gene. After pkD46 and PCR products were electro-transformed into strains, the resulting colonies were screened by kanamycin plates. Next, vector pCP20 was transformed into positive clones, and kanamycin resistance gene was eliminated. Positive clones were screened by colony PCR, and $l d h A$ mutant was acquired (Fig. 2B). All plasmids and mutants were confirmed by DNA sequencing. The primers used for PCR amplification are shown in Table S2.

\section{Results}

Performance of eGFP

Compared with Green Fluorescent Protein (GFP), eGFP manifests stronger fluorescence and has been widely used for protein labeling. The plasmids pET- $P_{l u x i}$ :egfp and

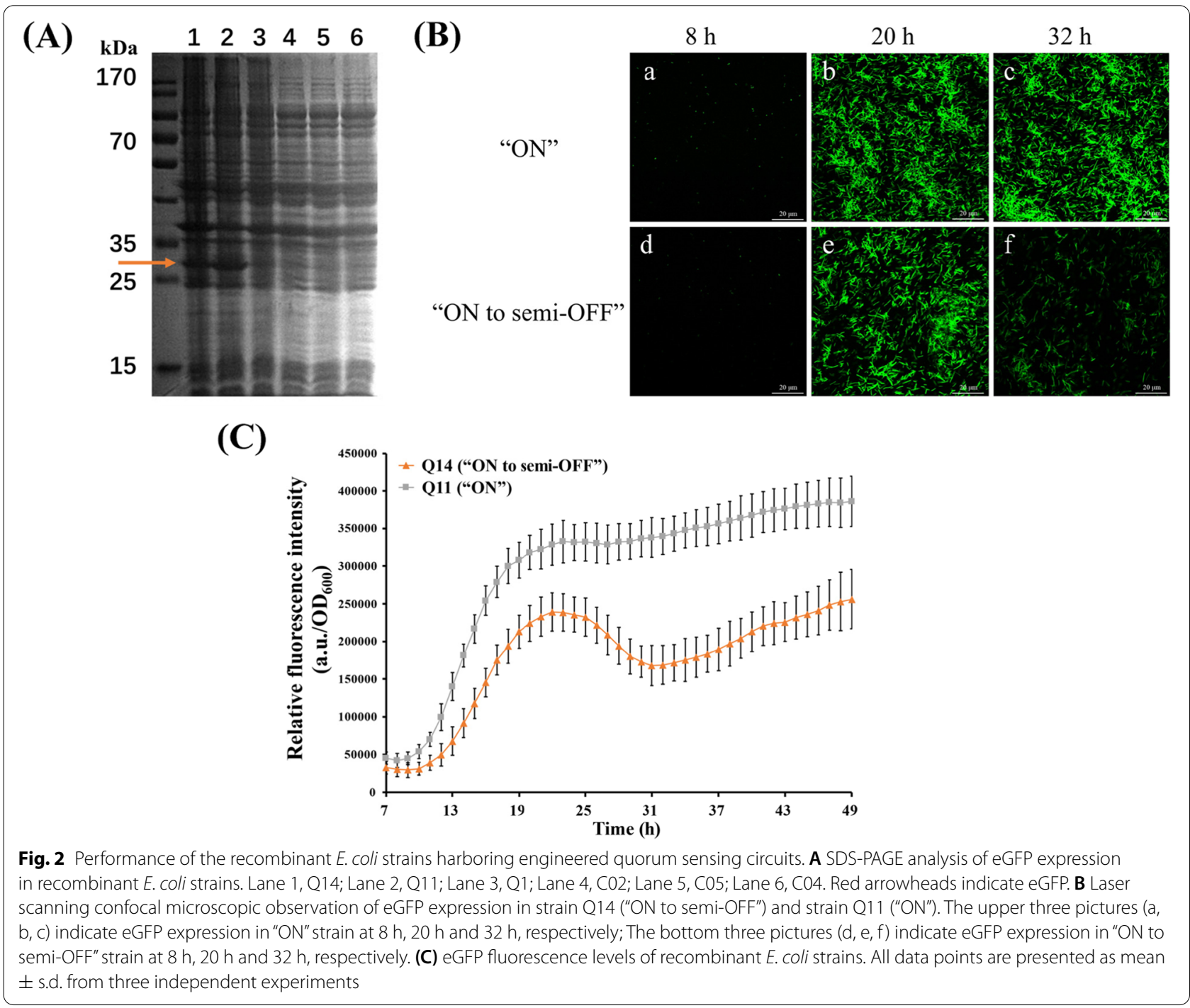


pET- $P_{\text {luxi }}:$ egfp-aiiA were constructed for gene expression in "ON" and "ON to semi-OFF" mode, respectively. To examine the "ON" mode, the strain Q11 was incubated in M9 medium. After centrifugation at $10,625 \mathrm{x}$ g and resuspension with $\mathrm{PBS}$, the "ON" strain demonstrated clear yellow-green light, whereas the control strains, Q01 and $\mathrm{C} 02$ did not (Fig. S1). This pre-experiment confirmed that the "ON" mode could trigger reporter gene expression. Next, we investigated the "ON to semi-OFF" strain Q14. As shown by the lane 1 and lane 2 in Fig. 2A, two significant bands exhibited molecular weight similar to eGFP (approximately $26.9 \mathrm{kDa}$ ), and the band in lane 2 was larger than that in lane 1, suggesting that eGFP was properly expressed in E. coli $\Delta l d h A$, and its expression level in "ON" strain was higher than that in "ON to semiOFF" strain. No significant band similar to eGFP was observed in lane 3 , lane 4 , lane 5 , and lane 6 of the control groups (Fig. 2A), indicating that an intact QS circuit is required for driving eGFP expression.

To determine how long eGFP expression lasted, Q14 ("ON to semi-OFF") and Q11 ("ON") were cultivated and observed using a laser scanning confocal microscope (Fig. 2B). Results showed that both "ON to semiOFF" and "ON" strains did not show fluorescence at $8 \mathrm{~h}$ (Fig. 2B, picture $a$ and $d$ ), with a significant increase at 20 h (Fig. 2B, picture $b$ and $e$ ). The "ON" strain showed continuous increase of fluorescence level from 20 to $32 \mathrm{~h}$ and eventually exceeded "ON to semi-OFF" strain (Fig. 2B, picture $e, f$, and $c$ ). Unlike "ON" strain, the "ON to semiOFF" strain showed decline of fluorescence from $20 \mathrm{~h}$ to $32 \mathrm{~h}$ (Fig. 2B, picture $b$ and $c$ ). To precisely determine eGFP expression, we investigated the relative fluorescence levels (fluorescence/ $\mathrm{OD}_{600}$ ). As shown in Fig. $2 \mathrm{C}$, the "ON" strain manifested high relative fluorescence and maintained it till $49 \mathrm{~h}$. This constant eGFP expression was induced by the accumulating AHL. Unlike "ON" strain, the "ON to semi-OFF" strain manifested less fluorescence. In particular, its relative fluorescence level was increasing until $22 \mathrm{~h}$ and then decreasing, which was possibly due to AHL degradation by AiiA. This decrease of fluorescence level lasted until $34 \mathrm{~h}$, and then maintained a relatively stable state called "semi-OFF". Such a state might be ascribed to incomplete AHL degradation. To confirm this prediction, UPLC-MS/MS was used to monitor AHL (3-oxo-C6-HSL) and its derivative (ring opening of 3-oxo-C6-HSL) in the broth of Q14 (Supplementary
Fig. 2D). The molecular ion $\left([\mathrm{M}+\mathrm{H}]^{+}=214.10,232.11\right)$ peaks were recorded by UPLC-MS. The peak of 214.10 at 3.49 min was further analyzed by tandem mass spectrometry (MS/MS) and then recorded two ion fragment $\left([\mathrm{M}+\mathrm{H}]^{+}=102.05,113.06\right)$ peaks, suggesting that these peaks belong to AHL (3-oxo-C6-HSL). The existing AHL and their ring opening derivatives in broth indicated that QS-controlled AiiA could not completely degrade AHL and thereby failed to completely shut down eGFP expression, leading to "semi-OFF" state.

\section{Performance of the recombinant strains overexpressing IdhA}

Given that the two QS circuits ("ON" and "ON to semiOFF") worked properly in E. coli, we next applied them to regulate $l d h A$ expression. To evaluate LdhA expression, we measured the specific activity of LdhA in Q12 ("ON") and Q15 ("ON to semi-OFF"). We found that the LdhA specific activity of Q15 increased in the first $20 \mathrm{~h}$ and then remarkably decreased, while that of Q12 increased in this first $32 \mathrm{~h}$ and then slightly decreased (Fig. 3A). Clearly, the fluctuation of LdhA specific activity was roughly consistent with the expression level of eGFP shown in Fig. 2B. Moreover, the $l d h A$-overexpressing "ON" strain entered the logarithmic growth phase slowly, with $\mathrm{OD}_{600}$ of 0.205 at $10 \mathrm{~h}$, but its maximum $\mathrm{OD}_{600}$ was 0.722 which was only lower than the strain harboring empty vector (Fig. 3B). In contrast, the "ON to semi-OFF" strain showed a shorter lag phase and lower growth rate compared to the "ON" strain. This "ON to semi-OFF" strain presented an $\mathrm{OD}_{600}$ value similar to the strain harboring empty vector in the first $8 \mathrm{~h}$, and this $\mathrm{OD}_{600}$ value was exceeded by the "ON" strain at $16 \mathrm{~h}$. As for glucose consumption, except for the strains harboring empty vector, all other strains did not demonstrate a significant difference in the first $6 \mathrm{~h}$ (Fig. 3C). This finding is consistent with lag phase growth, and the glucose consumption of Q12 was higher than that of C02, C01, and "ON to semi-OFF" strains. Furthermore, the strain Q12 exhibited $0.1163 \mathrm{~g} \mathrm{~h}^{-1}$ of glucose consumption, which is the highest except for the strains harboring empty vector.

Given the increase of growth rate and glucose consumption of Q12, we speculated that QS-dependent dynamic regulation of $l d h A$ expression might affect glucose metabolism. Quantitative real-time PCR was thus conducted to determine the relative transcriptional levels

\footnotetext{
(See figure on next page.)

Fig. 3 Shake-flask cultivation of the recombinant E. coli strains. A Comparison of LdhA specific activities in two different mode strains that Q12 and Q15. B Cell growth in shake flask of strains. C Glucose consumption in shake flask. D Gene transcription of the strain overexpressing IdhA by "ON" mode. IdhA, D-lactate dehydrogenase coding gene; gapA and gapC, GAPDH coding genes; ptsH, PTS phosphocarrier protein coding genes; ptsl, PTS enzyme I coding gene; $p y k F$, pyruvate kinase coding gene. $\mathbf{E}$ Comparison of gene transcription in Q12 upon $12 \mathrm{~h}$ and $22 \mathrm{~h}$ seed culture. $\mathbf{F}$ D-lactic acid. G Acetic acid. All data are presented as mean \pm s.d. from three independent experiments. The statistical analysis is based on Mann-Whitney $U$ test. ${ }^{*} P<0.05$ and ${ }^{*} P<0.01$
} 
(A)

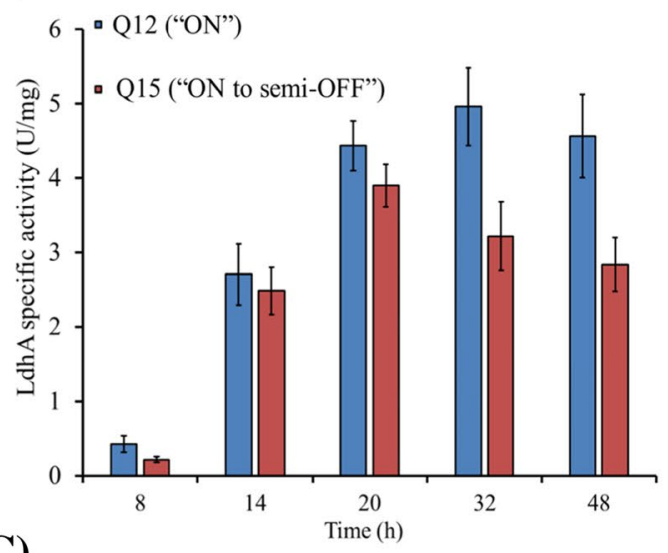

(C)

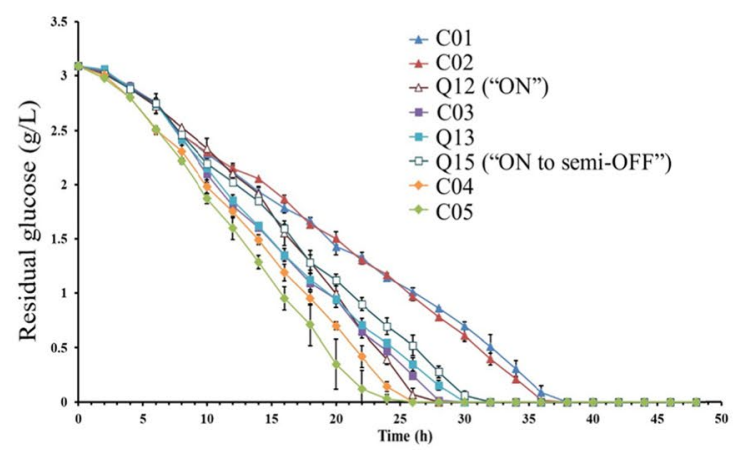

(E)

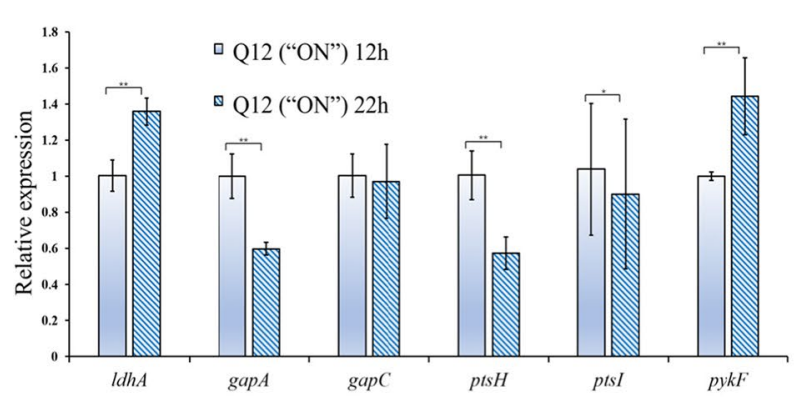

(B)

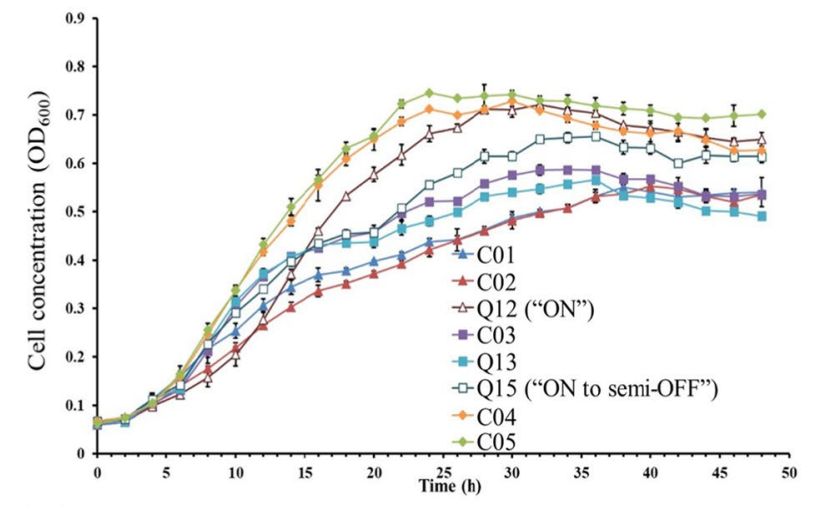

(D)

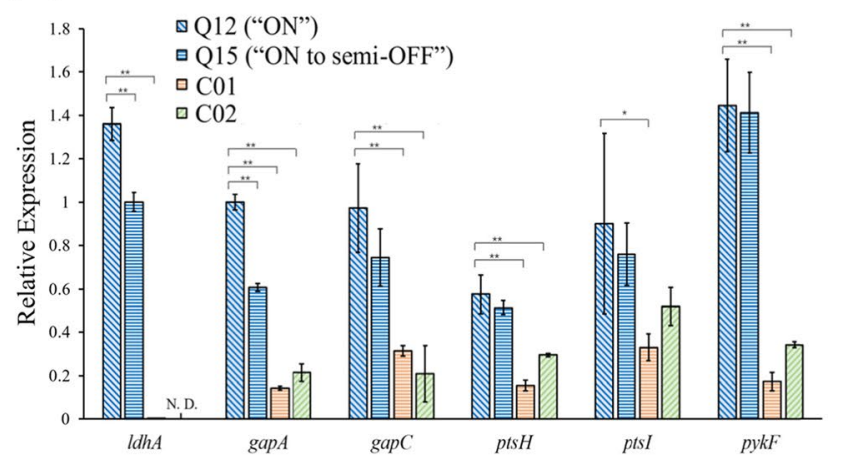

(F)

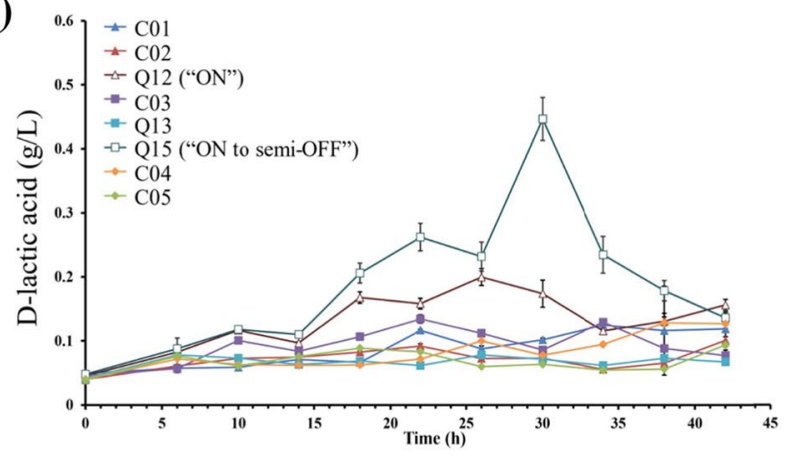

(G)

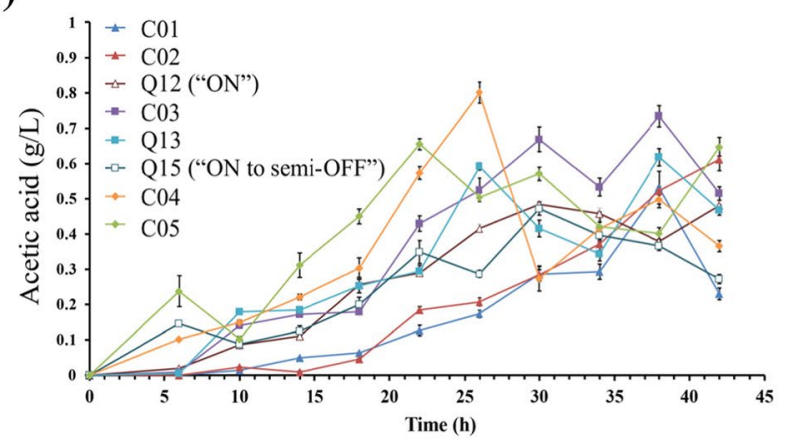

Fig. 3 (See legend on previous page.) 
of key enzyme genes related to glucose utilization. The key enzyme genes include $p t s H$ and $p t s I$ that encode enzyme I (EI) and histidine phosphocarrier protein (Hpr) in PTS, respectively, and the genes that encode pyruvate kinase I (PykF) and glyceraldehyde-3-phosphate dehydrogenase (GAPDH, an isoenzyme of GapA and GapC). PykF and GAPDH are key for $E$. coli glycolysis. As shown in Fig. 3D, almost all examined genes in strains Q12 and Q15 displayed enhanced transcription compared to those in control strains $\left(* P<0.05\right.$ and $\left.{ }^{* *} P<0.01\right)$, suggesting that the LdhA expression in "ON" and "ON to semi-OFF" strains activated PTS system and glycolysis, which therefore accelerated glucose uptake. This might compensate the decreased cell growth due to production formation in lag phase. Apart from the above experiments, we also investigated the gene expression of Q12 and Q15 at $12 \mathrm{~h}$ and $22 \mathrm{~h}$. Results showed that the genes $l d h A$ and $p y k F$ in both Q12 and Q15 were up-regulated from $12 \mathrm{~h}$ to $22 \mathrm{~h}$, while other genes in Q12 were down-regulated (Fig. 3E), indicating that QS-mediated $l d h A$ expression significantly up-regulated the key enzyme genes related to glycolysis and PTS system in a non-proportional way.

Furthermore, we investigated the formation of acids under QS-based dynamic control. As shown in Fig. 3F, the $l d h A$ mutants harboring vector pluxIR (for AHL synthesis) but without overexpressing $l d h A$ produced less D-lactic acid, as compared with the $l d h A$ mutants overexpressing both AHL synthesis gene and $l d h A$. For the reference strains, the ldhA mutant strain $\mathrm{C} 05$ produced only 28.23\% D-lactic acid as compared to the strain C04, indicating that $l d h A$ was key for D-lactic acid production. To determine whether $l d h A$ was solely controlled by the engineered QS circuit, ldhA was deleted from the $E$. coli genome but inserted into downstream of QS promoter, leading to vector $\mathrm{pET}-P_{\text {luxi }} l d h A$, or inserted between the promoter and aiiA gene, resulting in vector $\mathrm{pET}-P_{\text {luxi }}$ ldhA-aiiA. The corresponding recombinant strains were named Q12 and Q15, respectively. We found that Q15 ("ON to semi-OFF") produced more D-lactic acid, and presented the highest yield and spacetime yield compared with Q12 ("ON") and the control strains. In addition, while the strain Q12 ("ON") presented $0.2295 \mathrm{~g} / \mathrm{L}$ of maximum yield and $0.005526 \mathrm{~g} / \mathrm{h} / \mathrm{L}$ of space-time yield, the strain Q15 ("ON to semi-OFF") presented $0.4464 \mathrm{~g} / \mathrm{L}$ of maximum yield and 0.01488 $\mathrm{g} / \mathrm{h} / \mathrm{L}$ of space-time yield, which were $94.5 \%$ and $169.2 \%$ increase in maximum yield and space-time yield, respectively, as compared with Q12 ("ON"). Surprisingly, compared with the "ON" strain Q12, the "ON to semi-OFF" strain Q15 demonstrated 2.3-fold increase in maximum D-lactic acid titer. As the main byproduct in lactic acid production, acetic acid occupies a lot of carbon flux from pyruvate. As shown in Fig. 3G, acetic acid formation was associated with growth conditions, and Q12 and Q15 showed similar fluctuation in levels of acetic acid and D-lactic acid.

Given that the "ON to semi-OFF" strain outperformed "ON" strain in the production of lactic acid (Fig. 3F), we next ameliorated the tunability of "ON to semi-OFF" circuit and investigated its impact on lactic acid production. Since AiiA degrades AHL, we conjecture that the transcription level of aiiA might affect QS-mediated "On" and "Off" of gene expression. Moreover, considering ribosome binding site (RBS) markedly affects transcription (Salis et al. 2009; Pfleger et al. 2006), we adjusted the AiiA expression level by altering RBS. In doing so, two distinct RBS, which are respectively stronger and weaker than the previously validated aiiA RBS in vector pET$\mathrm{P}_{\text {luxil }}:$ ldhA-aiiA (Levin-Karp et al. 2013), were separately inserted the upstream of aiiA gene, leading to two recombinant plasmids pET- $\mathrm{P}_{\text {luxi }}:$ ldhA-aiiA(strong) and pET$\mathrm{P}_{\text {luxi }}:$ ldhA-aiiA(weak), respectively. Afterwards, the two recombinant plasmids were separately co-transformed with vector pluxIR into $E$. coli, leading to two "ON to semi-OFF" strains named Q17 and Q16 (Fig. 4A). The two "ON to semi-OFF" strains were compared with the aforementioned strain Q15. Real-time PCR showed that after $30 \mathrm{~h}$ cultivation, the transcription level of the strain Q17 was 4.2 and 40.9 times that of the control strains Q15 and Q16, respectively (Fig. 4B), indicating that RBS positively affected aiiA transcription. To disentangle the impact of aiiA transcription on $l d h A$ expression, the aforementioned three strains were investigated for their LdhA activity. As shown in Fig. 4C, in the first $20 \mathrm{~h}$, all three strains showed rapid increase in LdhA activity, and the enhancement in descending order was Q16, Q15, and Q17. These results suggested that QS system manifested "ON" state, and $l d h A$ was rapidly expressed. Notably, the strain Q16 showed the highest level of $l d h A$ expression (Fig. 4C). After $20 \mathrm{~h}$ cultivation, the strains Q15 and Q17 showed a decline in LdhA activity, and the latter strain exhibited lower LdhA activity. Interestingly, the LdhA activity of strain Q16 did not decline until $32 \mathrm{~h}$. These results suggested that after $20 \mathrm{~h}$ cultivation the strain employing moderate or strong aiiA RBS showed a decrease in LdhA activity because the expressed AiiA repressed the QS-driven ldhA expression earlier, and QS was switched to "semi-OFF" state. By contrast, the strain employing weak aiiA RBS showed LdhA degradation after $32 \mathrm{~h}$, which was similar to the behavior of "ON" strain, indicating that the QS circuit employing weak aiiA RBS was less switched to "semi-OFF" state compared to the QS circuit employing moderate or strong aiiA RBS. Lastly, we investigated D-lactic acid formation at $30 \mathrm{~h}$ (Fig. 4D). Compared with reference strain E. coli ( $\Delta l d h A /$ pET-P ${ }_{\text {luxil }}$ ldhA-aiiA/pluxIR), the strains Q17 and Q16 demonstrated $55.6 \%$ and $35.2 \%$ decrease in the production 

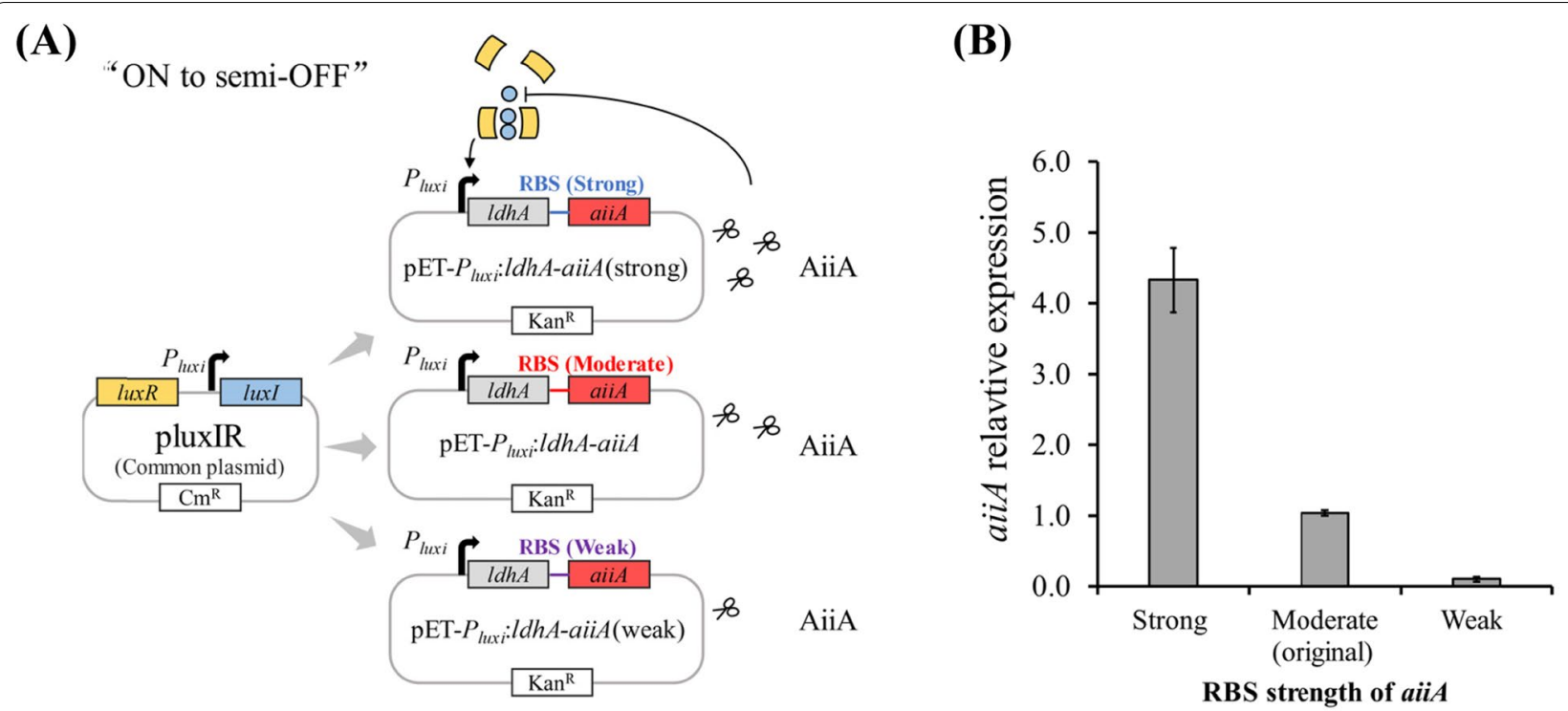

(C)

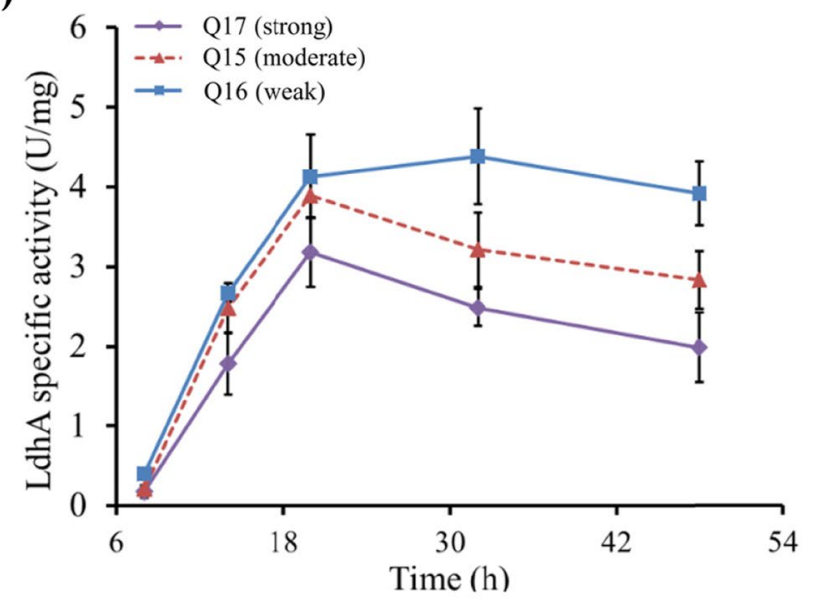

(D)

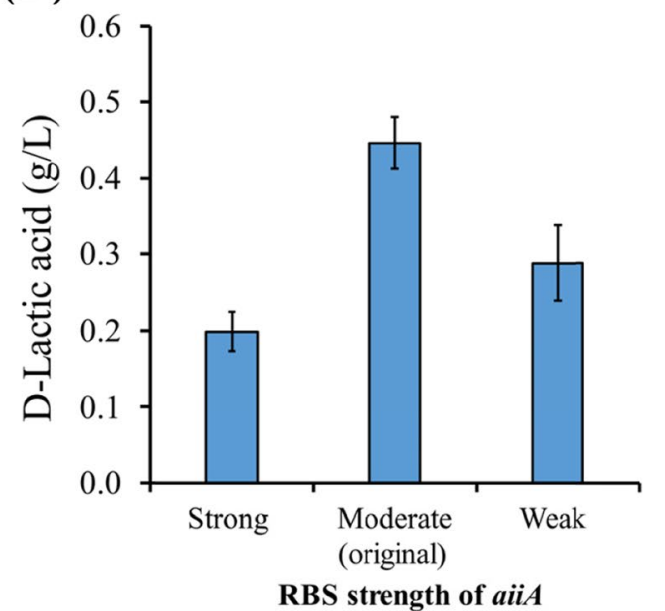

Fig. 4 Exploring the effects of different AiiA expression level on the production of D-lactic acid by the "ON to semi-OFF" strain. A Schematic diagram of "ON to semi-OFF" strains with different AiiA expression levels. Each strain harbors two vectors, and the vector pluxIR is owned by all strains. pET-Pluxi:IdhA-aiiA (strong), the recombinant vector coexpressing IdhA and aii A, and the latter using a strong-strength RBS. pET-Pluxi:IdhA-aiiA, the recombinant vector coexpressing $/ d h A$ and aiiA, and the latter using a medium-strength RBS, the original RBS was used for overexpressing $/ d h A$. pET-Pluxi:IdhA-aiiA(weak), the recombinant vector coexpressing IdhA and aiiA, and the latter using a medium-strength RBS. B Comparison of aiiA transcription levels in Q17, Q15, and Q16. C Comparison of LdhA-specific activities. D Comparison of D-lactic acid titer. All data are presented as mean \pm s.d. from three independent experiments

of D-lactic acid, respectively. These results indicated that the transcriptional up-regulation of aiiA led to a significant decrease in $l d h A$ expression and lactic acid formation. On the other hand, the transcriptional down-regulation of aiiA resulted in a transcription level of $l d h A$ similar to the "ON" state, which also constrained D-lactic acid formation. Taken together, the "ON to semi-OFF" outperformed "ON" in the production of D-lactic acid, as it demonstrated moderate aiiA transcription.
Lastly, we systematically assessed the performance of "ON" and "ON to semi-OFF" strains in cell growth, glucose consumption, and production of D-lactic acid and byproducts. The "ON" strain consumed more glucose and grew faster, while the "ON to semi-OFF" strain produced less acetic acid (byproduct) but more D-lactic acid (Fig. 5). In other words, the QS-based "ON" and "ON to semi-OFF" strains have their pros and cons in dynamic regulation of LdhA expression. 


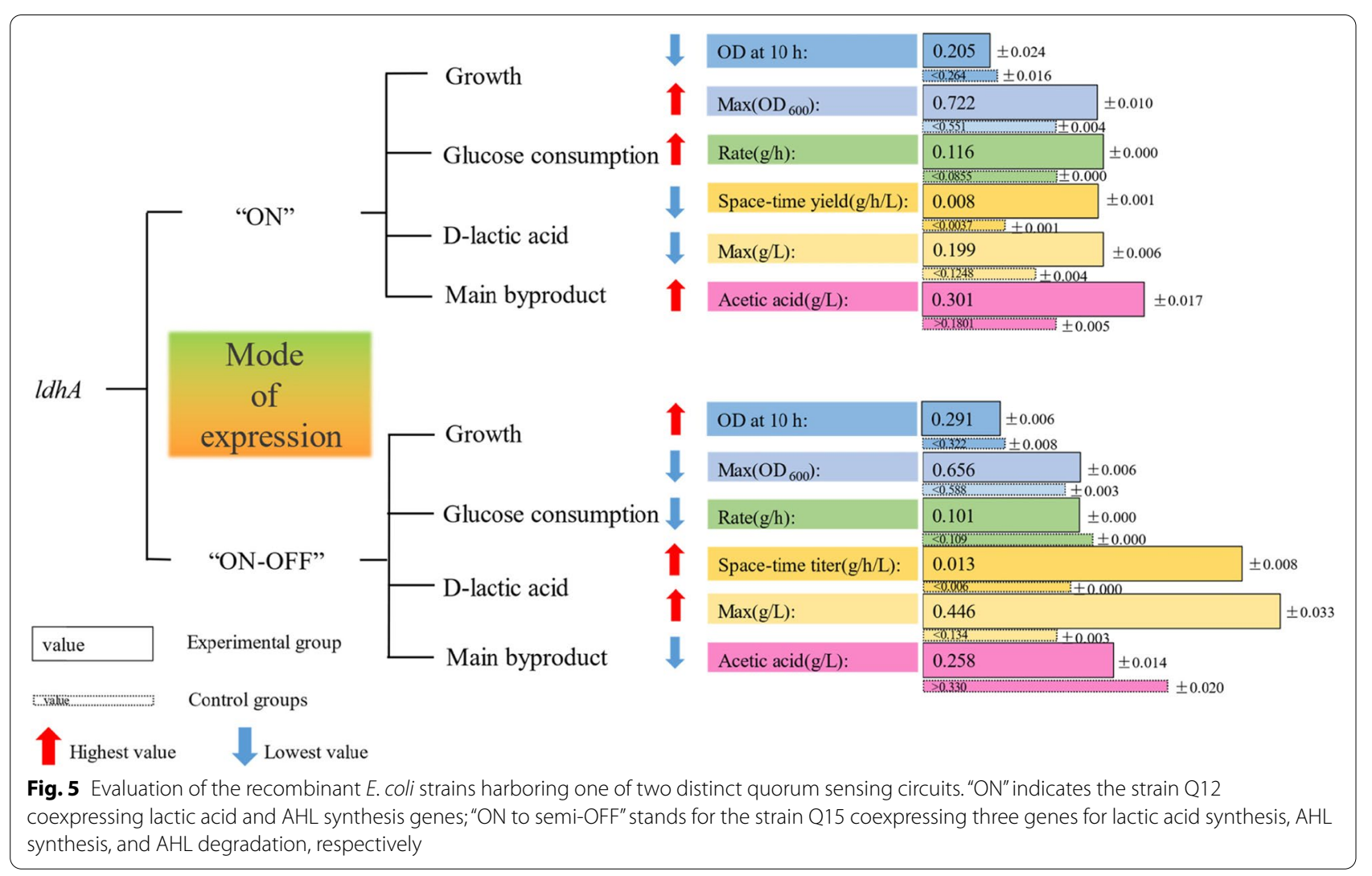

\section{Discussion}

Microbial production of D-lactic acid suffers growth inhibition due largely to overexpression. Dynamic regulation of gene expression can mitigate metabolic stress (Xu et al. 2014; Zhou et al. 2012). QS represents a typical dynamic gene regulation. Inspired by this, we engineered two recombinant $E$. coli strains harboring QS circuits. The "ON" strain harbors the expression cassette ldhA-LuxIR for the production of both lactic acid and AHL, while the "ON to semi-OFF" strain harbors both ldhA-luxIR and aiiA gene for the production of not only lactic acid and AHL but also AiiA which is an enzyme for AHL degradation (Fig. 1). Compared with the strain without LuxI-LuxR cassette, the "ON" strain coexpressing LuxI-LuxR and $l d h A$ showed $83.6 \%$ and $31.0 \%$ increase in growth rate and $\mathrm{OD}_{600}$, respectively (Fig. 3). Although the "ON to semi-OFF" strain grew slower than "ON" strain, it demonstrated a higher titer and productivity of D-lactic acid (Fig. 5). Compared with the reference strain harboring only $l d h A$ gene in vector, both the "ON" and "ON to semi-OFF" strains demonstrated synchronization between cell growth and D-lactic acid production. Although there exists a native LuxS/autoinducer 2 (AI-2) system in E. coli, which regulates cell density via AI-2 (Surette and Bassler, 1998), however, our experiment showed that the promoter $P_{l u x i}$ did not work in the absence of LuxI and LuxR. The above results indicated that QS can be exploited to coordinate cell growth and product formation. Compared with the "ON" strain, the "ON to semi-OFF" strain seems to be more appropriate for the production of lactic acid.

Active cell growth is a prerequisite for high-level production of desired metabolites. In this study, both "ON" and "ON to semi-OFF" strains showed enhanced cell growth when compared with the reference strain without the engineered QS circuit. This was primarily attributed to QS-dependent dynamic regulation of ldhA expression. Since LdhA catalyzes pyruvate to D-lactic acid, the excessive D-lactic acid leads to growth inhibition (Wang et al. 2018). The "ON" strain mitigated acid stress through the intensification of PTS and glycolysis, which thereby benefited cell growth. $E$. coli stringently controls lactic acid synthesis. Despite up to $5.55 \times 10^{4}$-fold increase in the relative expression of LdhA (Fig. 3D), only limited lactic acid was produced (Fig. 3F). By contrast, the QS-based "ON to semi-OFF" strain showed improved production of D-lactic acid. This was ascribed largely to the switch of $l d h A$ expression from "On" to "partial Off", thereby constraining acetic acid production (Fig. 3G). Compared with static 
strategies to coordinate cell growth and product formation, this QS-dependent dynamic strategy relies on timely sensing of cell density, and thus is appropriate for modulating the formation of metabolites especially those toxic to cells.

In this study, both "ON" and "ON to semi-OFF" strains produced a small amount of D-lactic acid (Figs. 3F, $4 \mathrm{D}$, and 5). The reasons may be the follows: (1) vectors imposed heavily on host cell due to consumption of cellular resources; (2) the AHL-inducible $\mathrm{P}_{\text {luxi }}$ is a weaker promoter compared to $\mathrm{T} 7, \mathrm{tac}$ and lac promoters; and (3) fermentation conditions were not optimized. To boost D-lactic acid production, the following may be considered. First, to minimize plasmid burden, the genes for AHL synthesis and degradation could be integrated into host genome, and only ldhA gene is left in vector. Second, tandem repetitive $P_{\text {luxi }}$ promoter could be employed to intensify LdhA expression and thereby divert pyruvate to D-lactic acid. Third, fermentation conditions including carbon source, nitrogen source, $\mathrm{pH}$ value, and dissolved oxygen could be systematically optimized. Finally, acid stress should be attenuated. To achieve this, in situ recovery of D-lactic acid from fermentation broth could be implemented. In addition, feedback inhibition could be minimized by engineering gene circuit (Kelly et al. 2018) or recruiting feedback inhibition-insensitive enzymes (Chen et al. 2014; Takpho et al. 2018).

Cell tolerance is usually controlled by multiple genes. CRISPR tools, especially CRISPR interference (CRISPRi), can be used to improve cell tolerance (Wang et al. 2019; $\mathrm{Xu}$ et al. 2019), as sgRNA array can lead dCas9 to multiple genes (Bikard et al. 2013). It has been shown that sgRNAs can be designed and synthesized to target multiple lactic acid pathways (Wang et al. 2018). CRISPRi can also regulate gene expression when combined with other tools. Indeed, microbes have bridged the gap between QS and CRISPR-Cas system. For instance, wild-type Pseudomonas aeruginosa recruits QS to govern CRISPRCas adaptive immune system (Patterson et al. 2016; Høyland-Kroghsbo et al., 2017), indicating the intrinsic connection between QS and CRISPR system. Inspired by this rationale, a pathway-independent genetic control module was constructed by linking QS to CRISPR. This engineered module can dynamically modulate gene expression (Gupta et al. 2017). More broadly, when this QS-based module was linked to metabolite sensor, a twolayered regulatory circuit was engineered (Doong et al. 2018). Apart from CRISPRi, RNAi can also be linked to QS circuit for dynamic control of the metabolic pathways in eukaryotes (Williams et al. 2015). Since QS is common in both bacteria and fungi, the method developed in the present study could prove useful for metabolic engineering of other species as well.

\section{Conclusions}

To coordinate cell growth and lactic acid synthesis in $E$. coli, we constructed two QS-based strains: one strain overexpressing AHL synthesis genes ("ON"), the other strain overexpressing both AHL synthesis and degradation gene (aiiA) ("ON to semi-OFF"). Compared to the reference strain harboring only $l d h A$ gene in vector, both "ON" and "ON to semi-OFF" strains showed synchronization between cell growth and D-lactic acid production, indicating that QS can be exploited to coordinate cell growth and product formation.

\section{Acknowledgements}

We thank Dr. ZHAO Peng for his assistance in material preparation.

\section{Authors' contributions}

C. G. and P. T. conceived and designed research. C. G., S. R., and H. J. conducted experiments. C. G. analyzed data. P.T. wrote the manuscript. The authors read and approved the final manuscript.

\section{Funding}

This study was funded by grants from the Hebei Project for Development of Science and Technology Guided by Central Universities (206Z2902G), National Key Research and Development Program of China (2018YFA0901800), and Project of Beijing Municipal Commission of Education (KZ201911417049).

Availability of data and materials

The data are available from the corresponding author on a reasonable request.

\section{Declarations}

Ethics approval and consent to participate

This article does not contain any studies with human participants or animals performed by any of the authors.

\section{Consent for publication}

All authors approved the publication of this manuscript.

\section{Competing interests}

The authors declare that they have no competing interests.

Received: 23 August 2021 Accepted: 5 January 2022

Published online: 26 January 2022

\section{References}

Balestrino D, Haagensen JA, Rich C, Forestier C (2005) Characterization of type 2 quorum sensing in Klebsiella pneumoniae and relationship with biofilm formation. J Bacteriol 187(8):2870-2880

Bikard D, Jiang W, Samai P, Hochschild A, Zhang F, Marraffini LA (2013) Programmable repression and activation of bacterial gene expression using an engineered CRISPR-Cas system. Nucleic Acids Res 41(15):7429-7437

Bunch PK, Mat-Jan F, Lee N, Clark DP (1997) The IdhA gene encoding the fermentative lactate dehydrogenase of Escherichia coli. Microbiology 143(1):187-195

Chen Z, Bommareddy RR, Frank D, Rappert S, Zeng A-P (2014) Deregulation of feedback inhibition of phosphoenolpyruvate carboxylase for improved lysine production in Corynebacterium glutamicum. Appl Environ Microbiol 80(4):1388-1393

Datsenko KA, Wanner BL (2000) One-step inactivation of chromosomal genes in Escherichia coli K-12 using PCR products. Proc Natl Acad Sci USA 97(12):6640-6645

Din MO, Danino T, Prindle A, Skalak M, Selimkhanov J, Allen K, Julio E, Atolia E, Tsimring LS, Bhatia SN (2016) Synchronized cycles of bacterial lysis for in vivo delivery. Nature 536(7614):81-85 
Dinh CV, Prather KL (2019) Development of an autonomous and bifunctional quorum-sensing circuit for metabolic flux control in engineered Escherichia coli. Proc Natl Acad Sci USA 116(51):25562-25568

Dong $Y H, X u J L$, Li XZ, Zhang LH (2000) AiiA, an enzyme that inactivates the acylhomoserine lactone quorum-sensing signal and attenuates the virulence of Erwinia carotovora. Proc Natl Acad Sci USA 97(7):3526-3531

Dong YH, Wang LH, Xu JL, Zhang HB, Zhang XF, Zhang LH (2001) Quenching quorum-sensing-dependent bacterial infection by an $\mathrm{N}$-acyl homoserine lactonase. Nature 411(6839):813-817

Dong YH, Gusti AR, Zhang Q, Xu JL, Zhang LH (2002) Identification of quorumquenching $\mathrm{N}$-acyl homoserine lactonases from Bacillus species. Appl Environ Microbiol 68(4):1754-1759

Doong SJ, Gupta A, Prather KL (2018) Layered dynamic regulation for improving metabolic pathway productivity in Escherichia coli. Proc Natl Acad Sci USA 115(12):2964-2969

Fuqua WC, Winans SC, Greenberg EP (1994) Quorum sensing in bacteria: the LuxR-Luxl family of cell density-responsive transcriptional regulators. J Bacteriol 176(2):269-275

Ge C, Sheng HK, Chen X, Shen XL, Sun XX, Yan YJ, Jia W, Yuan QP (2020) Quorum sensing system used as a tool in metabolic engineering. Biotechnol J 15(6):1900360

Gupta A, Reizman IMB, Reisch CR, Prather KL (2017) Dynamic regulation of metabolic flux in engineered bacteria using a pathway-independent quorum-sensing circuit. Nat Biotechnol 35(3):273-279

Harder BJ, Bettenbrock K, Klamt S (2018) Temperature-dependent dynamic control of the TCA cycle increases volumetric productivity of itaconic acid production by Escherichia coli. Biotechnol Bioeng 115(1):156-164

Høyland-Kroghsbo NM, Paczkowski J, Mukherjee S, Broniewski J, Westra E, Bondy-Denomy J, Bassler BL (2017) Quorum sensing controls the Pseudomonas aeruginosa CRISPR-Cas adaptive immune system. Proc Natl Acad Sci USA 114(1):131-135

Jiang XR, Yan X, Yu LP, Liu XY, Chen GQ (2021) Hyperproduction of 3-hydroxypropionate by Halomonas bluephagenesis. Nat Commun 12(1):1513

Kaur G, Srivastava A, Chand S (2015) Debottlenecking product inhibition in 1,3-propanediol fermentation by in-situ product recovery. Bioresour Technol 197:451-457

Kelly CL, Harris AWK, Steel H, Hancock EJ, Heap JT, Papachristodoulou A (2018) Synthetic negative feedback circuits using engineered small RNAs. Nucleic Acids Res 46(18):9875-9889

Kim EM, Woo HM, Tian T, Yilmaz S, Javidpour P, Keasling JD, Lee TS (2017) Autonomous control of metabolic state by a quorum sensing (QS)-mediated regulator for bisabolene production in engineered E. coli. Metab Eng 44:325-336

Lan El, Liao JC (2012) ATP drives direct photosynthetic production of 1-butanol in cyanobacteria. Proc Natl Acad Sci USA 109(16):6018-6023

Levin-Karp A, Barenholz U, Bareia T, Dayagi M, Zelcbuch L, Antonovsky N, Noor E, Milo R (2013) Quantifying translational coupling in E. coli synthetic operons using RBS modulation and fluorescent reporters. ACS Synth Biol 2(6):327-336

Ling C, Qiao GQ, Shuai BW, Olavarria K, Yin J, Xiang RJ, Song KN, Shen YH, Guo Y, Chen GQ (2018) Engineering NADH/NAD+ ratio in Halomonas bluephagenesis for enhanced production of polyhydroxyalkanoates (PHA). Metab Eng 49:275-286

Liu J, Li H, Xiong H, Xie X, Chen N, Zhao G, Caiyin Q, Zhu H, Qiao J (2019) Twostage carbon distribution and cofactor generation for improving L-threonine production of Escherichia coli. Biotechnol Bioeng 116(1):110-120

Lou W, Tan X, Song K, Zhang S, Luan G, Li C, Lu X (2018) A specific single nucleotide polymorphism in the ATP synthase gene significantly improves environmental stress tolerance of Synechococcus elongatus PCC 7942. Appl Environ Microbiol 84(18):e01222-e01218

Mazumdar S, Clomburg JM, Gonzalez R (2010) Escherichia coli strains engineered for homofermentative production of D-lactic acid from glycerol. Appl Environ Microbiol 76(13): 4327-4336

Moreno-Gámez S, Sorg RA, Domenech A, Kjos M, Weissing FJ, van Doorn GS, Veening J-W (2017) Quorum sensing integrates environmental cues, cell density and cell history to control bacterial competence. Nat Commun $8(1): 1-12$

Papenfort K, Bassler BL (2016) Quorum sensing signal-response systems in Gram-negative bacteria. Nat Rev Microbiol 14(9):576-588

Patterson AG, Jackson SA, Taylor C, Evans GB, Salmond GP, Przybilski R, Staals RH, Fineran PC (2016) Quorum sensing controls adaptive immunity through the regulation of multiple CRISPR-Cas systems. Mol Cell 64(6):1102-1108

Peters G, De Paepe B, De Wannemaeker L, Duchi D, Maertens J, Lammertyn J De Mey M (2018) Development of $\mathrm{N}$-acetylneuraminic acid responsive biosensors based on the transcriptional regulator NanR. Biotechnol Bioeng 115(7):1855-1865

Pfleger BF, Pitera DJ, Smolke CD, Keasling JD (2006) Combinatorial engineering of intergenic regions in operons tunes expression of multiple genes. Nat Biotechnol 24(8):1027-1032

Salis HM, Mirsky EA, Voigt CA (2009) Automated design of synthetic ribosome binding sites to control protein expression. Nat Biotechnol 27(10):946-950

Sun S, Zhang H, Lu S, Lai C, Liu H, Zhu H (2016) The metabolic flux regulation of Klebsiella pneumoniae based on quorum sensing system. Sci Rep $6(1): 1-9$

Surette MG, Bassler BL (1998) Quorum sensing in Escherichia coli and Salmonella typhimurium. Proc Natl Acad Sci USA 95(12):7046-7050

Takpho N, Watanabe D, Takagi H (2018) High-level production of valine by expression of the feedback inhibition-insensitive acetohydroxyacid synthase in Saccharomyces cerevisiae. Metab Eng 46:60-67

Tan SZ, Prather KL (2017) Dynamic pathway regulation: recent advances and methods of construction. Curr Opin Chem Biol 41:28-35

Thomas PW, Stone EM, Costello AL, Tierney DL, Fast W (2005) The quorumquenching lactonase from Bacillus thuringiensis is a metalloprotein. Biochemistry 44(20):7559-7569

Wang J, Zhao P, Li Y, Xu L, Tian P (2018) Engineering CRISPR interference system in Klebsiella pneumoniae for attenuating lactic acid synthesis. Microb Cell Factories 17(1):1-12

Wang T, Wang M, Zhang Q, Cao S, Li X, Qi Z, Tan Y, You Y, Bi Y, Song Y (2019) Reversible gene expression control in Yersinia pestis by using an optimized CRISPR interference system. Appl Environ Microbiol 85(12):e00097-e00019

Williams T, Averesch N, Winter G, Plan M, Vickers C, Nielsen L, Krömer J (2015) Quorum-sensing linked RNA interference for dynamic metabolic pathway control in Saccharomyces cerevisiae. Metab Eng 29:124-134

Wu J, Bao M, Duan X, Zhou P, Chen CW, Gao, JH, Cheng SY, Zhuang QQ, Zhao ZJ (2020a) Developing a pathway-independent and full-autonomous global resource allocation strategy to dynamically switching phenotypic states. Nat commun, 11: 5521 | https://doi.org/10.1038/ s41467-020-19432-2

Wu J, Chen W, Zhang Y, Zhang X, Jin JM, Tang SY (2020b) Metabolic engineering for improved curcumin biosynthesis in Escherichia coli. J Agric Food Chem 68(39):10772-10779

Xu P, Li L, Zhang F, Stephanopoulos G, Koffas M (2014) Improving fatty acids production by engineering dynamic pathway regulation and metabolic control. Proc Natl Acad Sci USA 111(31):11299-11304

Xu X, Williams TC, Divne C, Pretorius IS, Paulsen IT (2019) Evolutionary engineering in Saccharomyces cerevisiae reveals a TRK1-dependent potassium influx mechanism for propionic acid tolerance. Biotechnol Biofuels 12(1):1-14

You L, Cox RS, Weiss R, Arnold FH (2004) Programmed population control by cell-cell communication and regulated killing. Nature 428(6985):868-871

Zhou S, Grabar TB, Shanmugam KT, Ingram LO (2006a) Betaine tripled the volumetric productivity of D (-)-lactate by Escherichia coli strain SZ132 in mineral salts medium. Biotechnol Lett 28(9):671-676

Zhou S, Shanmugam KT, Yomano LP, Grabar TB, Ingram LO (2006b) Fermentation of $12 \%(\mathrm{w} / \mathrm{v})$ glucose to $1.2 \mathrm{M}$ lactate by Escherichia coli strain SZ194 using mineral salts medium. Biotechnol Lett 28(9):663-670

Zhou L, Niu DD, Tian KM, Chen XZ, Prior BA, Shen W, Shi GY, Singh S, Wang ZX (2012) Genetically switched D-lactate production in Escherichia coli. Metab Eng 14(5):560-568

\section{Publisher's Note}

Springer Nature remains neutral with regard to jurisdictional claims in published maps and institutional affiliations. 